\title{
Women's compliance with nutrition and lifestyle recommendations before pregnancy: general population cohort study
}

\begin{abstract}
Hazel M Inskip, professor of statistical epidemiology, Sarah R Crozier, statistician, Keith M Godfrey, professor of epidemiology and human development, Sharon E Borland, dietitian, Cyrus Cooper, professor of rheumatology and director, Siân M Robinson, principal research fellow in nutrition, for the Southampton Women's Survey Study Group
\end{abstract}

MRC Epidemiology Resource Centre, University of Southampton, Southampton General Hospital, Southampton S016 6YD

Correspondence to: H M Inskip hmi@mrc.soton.ac.uk

Cite this as: $B M J$ 2009;338:b481 doi:10.1136/bmj.b481

\section{ABSTRACT}

Objective To examine the extent to which women planning a pregnancy comply with recommendations for nutrition and lifestyle.

Design Prospective cohort study.

Setting Southampton, United Kingdom.

Participants 12445 non-pregnant women aged 20-34

emphasis is on advice for women who are planning a pregnancy.

Impaired fetal development and poor growth in infancy have been associated with increased risks of coronary heart disease, stroke, type 2 diabetes mellitus, the metabolic syndrome, and osteoporosis in later life. ${ }^{5}$ In recent years there has been increasing focus on recruited to the Southampton Women's Survey through general practices, 238 of whom became pregnant within three months of being interviewed.

Main outcome measures Folic acid supplement intake, alcohol consumption, smoking, diet, and physical activity before pregnancy.

Results The 238 women who became pregnant within three months of the interview were only marginally more likely to comply with recommendations for those planning a pregnancy than those who did not become pregnant in this period. Among those who became pregnant, $2.9 \%$ (95\% confidence interval $1.2 \%$ to $6.0 \%$ ) were taking 400 $\mu \mathrm{g}$ or more of folic acid supplements a day and drinking four or fewer units of alcohol a week, compared with $0.66 \%(0.52 \%$ to $0.82 \%)$ of those who did not become pregnant. $74 \%$ of those who became pregnant were nonsmokers compared with $69 \%$ of those who did not become pregnant $(P=0.08)$. Women in both groups were equally likely to consume five or more portions of fruit and vegetables a day ( $53 \%$ in each group, $\mathrm{P}=1.0$ ), but only $57 \%$ of those who became pregnant had taken any strenuous exercise in the past three months compared with $64 \%$ in those who did not become pregnant $(\mathrm{P}=0.03)$. Conclusion Only a small proportion of women planning a pregnancy follow the recommendations for nutrition and lifestyle. Greater publicity for the recommendations is needed, but as many pregnancies are unplanned, improved nutrition and lifestyles of women of childbearing age is also required.

\section{INTRODUCTION}

Advice on nutrition and lifestyle during pregnancy is widely available from health practitioners, the inter net, ${ }^{1-4}$ magazines, and other publications. Much less optimising women's nutrition and lifestyle in the periconceptional period, as this is a key time for fetal development. ${ }^{6}$ For example, clinical trials have shown that folic acid supplementation during the periconceptional period reduces the risk of neural tube defects. ${ }^{7}$ Women are, however, often unaware that they are pregnant for the first few weeks of embryonic life, and any subsequent changes miss the periconceptional period. Therefore promoting good health and nutrition before pregnancy may be at least as important as during pregnancy.

Recently the National Institute for Health and Clinical Excellence has reinforced this focus on the periconceptional period. Its guidance on nutrition of mothers and children ${ }^{8}$ not only advises improving the nutrition of pregnant women but also includes recommendations for those who may become pregnant. Indeed a review commissioned by the National Institute for Health and Clinical Excellence focused exclusively on interventions to improve the nutrition of women during the periconceptional period. ${ }^{9}$

Arguably the best known recommendation for women who are planning a pregnancy is to take 400 $\mu \mathrm{g}$ of folic acid a day in supplements to prevent neural tube defects. ${ }^{10}$ Until recently women planning a pregnancy in the United Kingdom were encouraged to limit alcohol consumption to one or two units, once or twice a week. In 2007 the advice was modified to urge women to avoid alcohol altogether or at most to consume one or two units (8-16 g of alcohol), once or twice a week. ${ }^{1-4}$ Additional advice is the same as for the general population, encouraging women to eat a healthy diet, take exercise, and avoid smoking. 
Table 1|Characteristics of women who did or did not become pregnant within three months of being interviewed. Values are numbers (percentages) unless stated otherwise

\begin{tabular}{lcc} 
Variables & Not pregnant within & Pregnant within \\
3 months & $12207(98)$ & $238(2)$ \\
Study sample & $28.5(24.7-31.8)$ & $28.9(25.6-31.3)$ \\
\hline Median (interquartile range) age (years) & & \\
\hline Highest educational qualification: & $706(6)$ & $7(3)$ \\
\hline None & $1345(11)$ & $31(13)$ \\
\hline GCSE grades D-G & $3217(26)$ & $65(27)$ \\
\hline GCSE grades A*-C & $3629(30)$ & $16(29)$ \\
\hline A levels & $699(6)$ & $49(21)$ \\
\hline Higher national diploma or equivalent & $2547(21)$ & $29(12)$ \\
\hline University degree or above & $2163(18)$ & $24.3(21.8-28.9)$ \\
\hline In receipt of social security benefits & $163(159-167)$ & \\
\hline Median (interquartile range) height $(\mathrm{cm})$ & $24.1(21.8-27.5)$ & \\
\hline Median (interquartile range) body mass index $\left(\mathrm{kg} / \mathrm{m}^{2}\right)$ & & \\
\hline
\end{tabular}

Despite the information available for women planning a pregnancy, data are limited on how closely the recommendations are followed. Various surveys have asked pregnant women or those who have recently delivered a baby about their lifestyle and folic acid intake around conception. ${ }^{11-27}$ However, the information obtained in this way is subject to recall bias. To our knowledge no studies have assessed women drawn from the general population when they were not pregnant and followed to pregnancy and beyond.

Studies have shown that the median time to conception in those planning a pregnancy is two to three months. ${ }^{28-31}$ Using the Southampton Women's Survey, ${ }^{32}$ we examined the nutrition and lifestyle of interviewed women during the three months before they became pregnant and compared them with participants who were not pregnant during that period. We assessed the extent to which women comply with the recommendations for nutrition and lifestyle leading up to pregnancy.

\section{METHODS}

Between 1998 and 2002, 12583 women aged 20-34 and living in Southampton were recruited to the Southampton Women's Survey and interviewed in their homes by research nurses. Women were recruited through their general practices. The full details are published elsewhere. ${ }^{32}$ The focus of the study was to examine the factors operating before and during pregnancy on the growth and development of the fetus, infant, and child. Non-pregnant women were recruited and information recorded on their diet, physical activity, smoking, alcohol consumption, and use of nutritional supplements over the preceding three months. Diet was assessed using a 100 item food frequency questionnaire ${ }^{33}$ from which principal components analysis was used to derive a "prudent" diet score. ${ }^{34}$ High scores reflect diets in line with the healthy eating recommendations, characterised by high intakes of fruit, vegetables, wholemeal bread, rice, and pasta and low intakes of white bread, added sugar, and tinned vegetables. We derived the number of portions of fruit and vegetables consumed daily from the food frequency questionnaire. The women were asked about the brands of dietary supplements used, the amount taken daily, and how many days each supplement had been taken over the past three months. From these reported intakes, we derived the amount of folic acid taken in nutritional supplements over the three months before the interview and identified those women who reported taking $400 \mu \mathrm{g}$ or more of folic acid a day. Given that some women may only have started taking folic acid recently and that the required amount may have been taken on most but not all days, we also classified women according to whether or not they averaged an intake of $200 \mu \mathrm{g}$ or more folic acid a day over the previous three months.

When the women became pregnant they attended Southampton's Princess Anne Maternity Hospital for fetal ultrasonography at 11,19 , and 34 weeks' gestation. We collected data on menstruation and ultrasonography from the women early in pregnancy ${ }^{32}$ and estimated the date the pregnancy started using an algorithm that combined these data. For the main analyses we compared women who became pregnant within three months with those who did not. We did a similar analysis for women who became pregnant within one month of the interview, to see if those close to pregnancy at the interview were more likely to conform to the recommendations. Our data also enabled us to identify a further group of women who became pregnant 30 to 60 months after the interview to assess whether their lifestyles were more similar to the general population or to the group who became pregnant within three months.

\section{Statistical analysis}

We compared proportions using $\chi^{2}$ tests and, when appropriate, Fisher's exact tests, and we derived exact binomial confidence intervals. To compare continuous variables we used $t$ tests, with skewed data being transformed using a logarithmic transformation before analysis.

\section{RESULTS}

Thirty two of the 12583 women interviewed were outside the age range 20-34 and were therefore excluded. A further 106 women were excluded as calculations showed that they were already pregnant at the time of the interview. Data on 12445 women were thus available for analysis. Of these women, 238 became pregnant within three months of the interview.

Table 1 shows the personal characteristics of the women who did and did not become pregnant within three months. The only significant difference between the groups was the percentage in receipt of social security benefits: $12 \%$ of those who became pregnant and $18 \%$ of those who $\operatorname{did} \operatorname{not}(\mathrm{P}=0.03)$.

Table 2 summarises the ways in which the women conformed to both the general healthy lifestyle guidelines and the specific recommendations for those planning a pregnancy. The women who became pregnant within three months of the interview were 
slightly less likely to be smoking than those women who did not become pregnant $(74 \%$ v $69 \%$ were nonsmokers), but the difference did not reach statistical significance $(\mathrm{P}=0.08)$. They were, however, less likely to have taken any strenuous exercise in the three months before the interview $(\mathrm{P}=0.03)$. Their diets were marginally more healthy but the effect was small, and in both groups $53 \%$ of women reported consuming five or more portions of fruit and vegetables a day, as derived from the food frequency questionnaire.

Those women who became pregnant within three months consumed a median 4.0 units of alcohol a week, which corresponds to the upper limit recommended for women planning a pregnancy; for those who did not become pregnant the median was slightly higher at 4.8 units a week. The data were, however, strongly positively skewed, and some women reported high levels of alcohol consumption. As other reports quote means rather than medians, table 2 also shows mean intakes. Proportionally, more women who became pregnant consumed 14 units or less of alcohol a week compared with those who did not become pregnant $(85 \% v 80 \%)$, and this difference was of borderline significance. Among those consuming alcohol at the higher levels of more than 14 units a week, reported units consumed weekly differed little between those who did and did not become pregnant, with a median of 22 units a week in both groups.

Significant differences were seen in the expected direction between the groups for amount of alcohol

Table 2 |Compliance with general healthy lifestyle recommendations and specific prepregnancy recommendations in women who did or did not become pregnant within three months of being interviewed. Values are percentages ( $95 \%$ confidence intervals) unless stated otherwise

\begin{tabular}{|c|c|c|}
\hline Variables & $\begin{array}{l}\text { Not pregnant within } \\
3 \text { months }(n=12207)\end{array}$ & $\begin{array}{l}\text { Pregnant within } \\
3 \text { months }(n=238)\end{array}$ \\
\hline \multicolumn{3}{|l|}{ General healthy lifestyle recommendations } \\
\hline Not smoking & 69 (68 to 70$)$ & $74(68$ to 80$)$ \\
\hline \multicolumn{3}{|l|}{ Healthy eating: } \\
\hline Mean $(95 \% \mathrm{Cl})$ prudent diet score (SD) & $0.00(-0.02$ to 0.02$)$ & $0.07(-0.06$ to 0.19$)$ \\
\hline Consumes $\geq 5$ portions of fruit and vegetables daily & $53(52$ to 54$)$ & 53 (46 to 59$)$ \\
\hline Any strenuous activity in past 3 months* & 64 (63 to 65$)$ & 57 (50 to 63$)$ \\
\hline \multicolumn{3}{|l|}{ Specific prepregnancy recommendations } \\
\hline \multicolumn{3}{|l|}{ Alcohol intake: } \\
\hline $\begin{array}{l}\text { Median (interquartile range) units consumed per } \\
\text { week } \dagger\end{array}$ & $4.8(1.3-12.0)$ & $4.0(1.0-9.5)$ \\
\hline Mean (range) units consumed per week $\dagger$ & $9.0(0-251)$ & $7.6(0-92)$ \\
\hline Never & $10(9.5$ to 11$)$ & $7.6(4.5$ to 12$)$ \\
\hline$\leq 4$ units/week & $46(45$ to 46$)$ & 51 (44 to 57$)$ \\
\hline$\leq 14$ units/week $\ddagger$ & $80(79$ to 80$)$ & 85 (80 to 89$)$ \\
\hline \multicolumn{3}{|l|}{ Folic acid supplements in past 3 months: } \\
\hline Any§ & $26(25$ to 26$)$ & $44(37$ to 50$)$ \\
\hline$\geq 200 \mu \mathrm{g} /$ day§ & 4.4 (4.0 to 4.7$)$ & 19 (14 to 24$)$ \\
\hline$\geq 400 \mu \mathrm{g} /$ day§ & $1.1(0.91$ to 1.3$)$ & $5.5(2.9$ to 9.2$)$ \\
\hline$\leq 4$ units alcohol per week and folic acid $\geq 400 \mu \mathrm{g} /$ day§ & $0.66(0.52$ to 0.82$)$ & 2.9 (1.2 to 6.0$)$ \\
\hline \multicolumn{3}{|c|}{$\begin{array}{l}\text { Comparisons are not statistically significant at } 5 \% \text { level unless stated otherwise. } \\
{ }^{*} P=0.03 \text {. } \\
\dagger P=0.007 \text { for differences among those drinking any alcohol. } \\
\ddagger P=0.049 \\
\S P<0.001\end{array}$} \\
\hline
\end{tabular}

consumed on average and intake of folic acid from supplements. However, only $44 \%$ of the women who became pregnant had taken any folic acid supplements in the three months before the interview and only $5.5 \%$ had taken $400 \mu \mathrm{g}$ or more a day. At 11 weeks' gestation, 203 of the 238 women were interviewed and by this time $93 \%$ were taking some folic acid and $12 \%$ reported taking $400 \mu \mathrm{g}$ or more a day over the preceding three months.

Although the difference between the two groups was highly significant for conforming to the two specific recommendations on alcohol and folic acid intake before pregnancy, the actual differences were small. Only seven of the 238 women $(2.9 \%)$ who became pregnant were following these recommendations fully at the time of being interviewed, compared with $0.66 \%$ of those who did not become pregnant. Thus women who became pregnant were 4.5 times more likely to follow the recommendations than those who did not (relative risk 4.5, 95\% confidence interval 2.1 to 9.6), with an absolute difference in risk of $2.3 \%(95 \%$ confidence interval $1.2 \%$ to $3.4 \%$ ).

Only two of the 71 women $(2.8 \%)$ who became pregnant within one month of the interview reported complying with the recommendations on alcohol and folic acid intake at the time of the interview. Forty eight per cent were taking some folic acid, but this figure is only marginally higher than the $44 \%$ among the larger group of those who became pregnant within three months of the interview.

At interview, $55(23 \%)$ of the 238 women who became pregnant within three months of the interview had said that they did not anticipate trying for a baby in the next 12 months. Among this "unplanned" pregnancy group only one woman $(1.8 \%)$ who became pregnant within three months complied with the recommendations for alcohol and folic acid, but among the remainder, who were in some sense planning a pregnancy, the percentage was only slightly higher at $3.3 \%(n=6)$. Nonetheless, $48 \%$ of women who planned a pregnancy were taking some folic acid at the time of the interview compared with $29 \%$ among those in the unplanned pregnancy group $(\mathrm{P}=0.013)$.

An analysis of 263 women who became pregnant at 30 to 60 months after the interview showed that they were more similar to all women in the population than to those who became pregnant within three months of the interview. Sixty three $(24 \%)$ of these women were taking some folic acid in supplements at the time of the interview. This is closer to the overall percentage of $26 \%$ (difference $\mathrm{P}=0.5$ ) seen among all women who did not become pregnant within three months, than the $44 \%(\mathrm{P}<0.001)$ among those who did become pregnant in that time. This indicates that some women do alter their behaviours, albeit slightly, in the immediate few months before pregnancy, although the proportion of women is small.

\section{DISCUSSION}

Few women succeed in complying with the nutrition and lifestyle recommendations for planning a 
pregnancy; only $2.9 \%$ complied fully with the recommendations on alcohol and folic acid intake in the three months before becoming pregnant. Less than half the women who became pregnant within the three months of being interviewed were taking any folic acid supplements at the time of the interview. Although those who became pregnant within three months were slightly less likely to smoke and tended to eat a marginally more healthy diet, they were less likely to undertake strenuous exercise than those who did not become pregnant.

\section{Comparison with other studies}

Several studies asked women retrospectively about folic acid intake in the periconceptional period. ${ }^{11-27}$ Generally, fewer than half the women took any folic acid, comparable with our findings. In some studies less than $10 \%$ of women reported having taken folic acid. $^{1221}$ These studies are from a variety of countries, however, and the information provided to young women about preparing for pregnancy varies in content and detail.

Studies from Denmark and the United States have shown lower levels of alcohol consumption than found in our study. No alcohol consumption was reported by $28 \%$ of Danish couples currently planning a pregnancy, ${ }^{20}$ and retrospectively reported by $12 \%$ of Danish women who had planned their pregnancy.$^{35}$ In women in the US who were asked in pregnancy or after the birth of their child around 50\% reported drinking no alcohol in the months leading up to the pregnancy. ${ }^{131417}$ These abstinence rates are higher than in our study, although it should be noted that alcohol consumption in the general population varies widely by country. In the British general household survey mean weekly intakes of about 8 units of alcohol have been reported for women aged $25-44^{36}$ and these levels are more similar to those seen in our study, whether or not in the time leading up to pregnancy.

\section{Strengths and weaknesses}

The major strength of this study is that we obtained information about the women before they became pregnant. The women were asked about their lifestyles and diet as part of a general survey on health and were not influenced by their knowledge of whether they would become pregnant. Only at the end of the interview were they asked whether they anticipated planning a pregnancy in the next 12 months, so their pregnancy intentions should not have biased their answers. We believe that this is a unique study design in that all other studies have obtained information retrospectively and thus may be affected by recall bias, or they have focused specifically on women planning a pregnancy.

The Southampton Women's Survey is broadly representative of the general population of England and Wales except for a lower than average percentage of women from non-white ethnic groups. ${ }^{32}$ Some $75 \%$ of those women contacted agreed to take part, which is a high participation rate for studies on a general population.

We may have missed some women who became pregnant within three months of the interview as they moved away from the area. However, the number of such women is likely to be small, and given the large number of women who did not become pregnant, they will hardly have distorted the figures in that group in any noticeable way.

A limitation is that we asked about lifestyles and alcohol and folic acid intakes over the three months before the interview. Some women may have started planning their pregnancy during that time window, or after they had been interviewed but before they became pregnant. It is thus possible that some women were better equipped for their pregnancy than our data reveal. However, among women who became pregnant within one month of the interview the increase in those conforming to the recommendations was marginal. Even among women who indicated that they might be contemplating a pregnancy the percentages conforming to the recommendations were low.

\section{Interpretation and implications}

Our study shows that few women follow the recommendations for those preparing for pregnancy. This is not surprising, as women do not know when they will conceive. Planning for an event that may or may not occur is far from easy. Among the women who became pregnant within three months, $23 \%$ answered no at interview when asked if they intended to become pregnant within the next 12 months. This proportion is lower than the true unplanned pregnancy rate, as many of those women we have classified as planning a pregnancy may not have planned to become pregnant within the three month time window, and so, according to definitions used in other studies, their pregnancy would have been unplanned. Estimates of unplanned or unintended pregnancies elsewhere vary from about one third to more than a half of pregnancies. ${ }^{183738}$ Our rate of "unplanned" pregnancies cannot be compared directly with these other estimates because of the differences between definitions.

No amount of advice for planning a pregnancy will affect those who become pregnant unintentionally. Nonetheless, even for women who want to plan for pregnancy, the advice is not promoted widely. It is neither a high priority within the medical profession nor widely discussed in the media and among the general public. Thus it is not surprising that such a small proportion of women follow the advice.

In the period leading up to pregnancy the recommendations for smoking, exercise, and diet are similar to those for women in the general population. However, our data show that there are no significant improvements in compliance with the recommendations for smoking and diet among women in the time leading up to pregnancy. Those who became pregnant within three months of the interview were less likely to be taking strenuous exercise. This is hard to explain 


\section{WHAT IS ALREADY KNOWN ON THIS TOPIC}

Nutrition and lifestyle guidelines are provided for women planning pregnancies, but whether these are followed is unclear

Data on the general population have been obtained after women have become pregnant or given birth, and are prone recall bias

\section{WHAT THIS STUDY ADDS}

Few women adhere to the nutrition and lifestyle recommendations for planning a pregnancy Greater efforts are needed to improve compliance with the recommendations

unless women are influenced by perceptions about the risks of exercise in pregnancy.

Folic acid was taken in sufficient quantities by only a small percentage of women, and supplementation in the periconceptional period is considered important for the prevention of neural tube defects. ${ }^{10}$ However, folic acid intakes from supplements were higher among the women who became pregnant within three months of the interview than among those who did not. The comparison with women who became pregnant 30-60 months later indicates that our findings are not simply showing that women who are healthy enough to become pregnant at some time in the future follow health and lifestyle recommendations more closely. This is encouraging as it implies that messages about folic acid have reached some women and that they act on the advice. The percentages also increased in early pregnancy showing that considerably more women comply with the recommendations once they become pregnant. Nonetheless, women's intakes of folic acid supplements leading up to pregnancy generally fall far short of the recommendations.

In those who became pregnant within three months, median alcohol intakes before conception were slightly lower than in those women not planning a pregnancy. However, almost half of those who became pregnant within three months reported drinking at levels above the recommended limit for those planning a pregnancy that was in operation at the time of the study. Only 7.6\% of those who became pregnant within three months were not drinking any alcohol at the time of the interview, and it is only these women who would comply fully with the current recommendations for alcohol intake. Women may not want to admit to trying for a pregnancy, and cutting alcohol out of their lifestyle could be difficult. Once pregnant, many women do report lower levels of alcohol consumption than before pregnancy ${ }^{39}$ and so are aware of the recommendations for pregnant women. In a culture in which around a quarter of young women report drinking at levels that are in excess of 14 units a week (the maximum level recommended for women not planning a pregnancy), ${ }^{36}$ a noticeable downwards shift in alcohol consumption in the general population would be required before levels of alcohol consumption in those planning a pregnancy are likely to reduce to previously recommended levels. Reducing intake to zero would be an even greater challenge.
In conclusion, our data show limited evidence of changes in health behaviours before pregnancy. Higher percentages of women conform to recommendations during pregnancy ${ }^{39}$ indicating that change in behaviour is possible. This may indicate that the prepregnancy recommendations are not publicised widely enough. Although this might be improved by greater publicity of the recommendations, substantial rates of unplanned pregnancies ${ }^{183738}$ mean that greater efforts are needed to improve the nutrition and lifestyles in women of childbearing age.

We thank the general practitioners and midwives for their assistance with the survey; the Southampton Women's Survey Study Group for recruiting and interviewing the participants and processing the data; and the participants for their time and information.

Contributors: $\mathrm{HMI}$, KMG, SMR, and CC designed and ran the Southampton Women's Survey. HMI and SRC developed the idea for the analyses. HMI carried out the analyses. SEB and SMR interpreted the nutritional and dietary data. All authors discussed and interpreted the findings and contributed to the final report. HMI drafted the report and is guarantor. Funding: This component of the Southampton Women's Survey was funded by the UK Medical Research Council, the University of Southampton, and the Dunhill Medical Trust. None of the funders had any role in the design of this study; collection, analysis, and interpretation of the data; writing the report; or the decision to submit the article for publication.

Competing interests: None declared.

Ethical approval: The Southampton Women's Survey was approved by the Southampton and South West Hampshire local research ethics committee.

1 Food Standards Agency. Eat well, be well. 2008. www.eatwell.gov.uk/ agesandstages/pregnancy/.

2 Patient UK. Planning to become pregnant? 2008. www.patient.co.uk/ showdoc/23068728/.

3 Family Planning Association. Pregnant or trying to get pregnant. 2008. www.fpa.org.uk/information/leaflets/documents_and_pdfs/detail. cfm?contentid $=660 \# 2$.

4 US Department of Health \& Human Services. Healthy pregnancy. 2008. www.womenshealth.gov/pregnancy/index.cfm.

5 Gluckman PD, Hanson MA, Cooper C, Thornburg KL. Developmental pathways to future health and disease. NEngl/Med 2008;359:61-73.

6 Chapin RE, Robbins WA, Schieve LA, Sweeney AM, Tabacova SA, Tomashek KM. Off to a good start: the influence of pre- and periconceptional exposures, parental fertility, and nutrition on children's health. Environ Health Perspect 2004;112:69-78.

7 Wald N. Folic acid and the prevention of neural tube defects. Ann NY Acad Sci 1993;678:112-29.

8 National Institute for Health and Clinical Excellence public health guidance 11. Improving the nutrition of pregnant and breastfeeding mothers and children in low-income households. 2008. www.nice. org.uk/nicemedia/pdf/PH011guidance.pdf.

9 McFadden A, King SE, Moreton JA, McCormick F, D’Souza L, Wright K, et al. NICE maternal and child nutrition programme. Review 1: the effectiveness of public health interventions to promote nutrition of pre-conceptional women. 2008. www.nice.org.uk/nicemedia/pdf/ MCNReview1Preconception.pdf.

10 Scientific Advisory Committee on Nutrition. Folate and disease prevention. London: Stationery Office, 2006.

11 Amitai Y, Fisher N, Meiraz H, Baram N, Tounis M, Leventhal A. Preconceptional folic acid utilization in Israel: five years after the guidelines. Prev Med 2008;46:166-9.

12 Coll O, Pisa S, Palacio M, Quintó L, Cararach V. Awareness of the use of folic acid to prevent neural tube defects in a Mediterranean area. EurJ Obstet Gynecol Reprod Biol 2004;115:173-7.

13 D'Angelo D, Williams L, Morrow B, Cox S, Harris N, Harrison L, et al. Preconception and interconception health status of women who recently gave birth to a live-born infant-Pregnancy Risk Assessment Monitoring System (PRAMS), United States, 26 reporting areas, 2004 MMWR Surveill Summ 2007;56(10):1-35.

14 Floyd RL, Decouflé P, Hungerford DW. Alcohol use prior to pregnancy recognition. Am J Prev Med 1999;17:101-7.

15 ForsterDA, Wills G, Denning A, Bolger M. The use of folic acid and other vitamins before and during pregnancy in a group of women in Melbourne, Australia. Midwifery 2007:doi:10.1016/j.midw.2007.01.01. 
16 Goldberg BB, Alvarado S, Chavez C, Chen BH, Dick LM, Felix RJ, et al. Prevalence of periconceptional folic acid use and perceived barriers to the postgestation continuance of supplemental folic acid: survey results from a Teratogen Information Service. Birth Defects Res 2006;76(part A):193-9.

17 Hellerstedt WL, Pirie PL, Lando HA, Curry SJ, McBride CM, Grothaus LC, et al. Differences in preconceptional and prenatal behaviors in women with intended and unintended pregnancies. Am J Public Health 1998;88:663-6.

18 Herrick K, Kelly Y. Maternal health. In: Sproston K, Primatesta P, eds. Maternal and infant health. Health survey for England 2002. London: Stationery Office, 2003. www.archive2.official-documents.co.uk/ document/deps/doh/survey02/maih/maih.htm.

19 Howell F, Bedford D, O'Keefe B, Corcoran R. Folic acid and prevention of neural-tube defects. Lancet 1997;350:664-5.

20 Juhl M, Nyboe Andersen AM, Grønbaek M, Olsen J. Moderate alcohol consumption and waiting time to pregnancy. Hum Reprod 2001;16:2705-9.

21 Li Z, Ren A, Zhang L, Liu J, Li Z. Periconceptional use of folic acid in Shanxi Province of northern China. Public Health Nutr 2007;10:471-6.

22 McGovern E, Moss H, Grewal G, Taylor A, Bjornsson S, Pell J. Factors affecting the use of folic acid supplements in pregnant women in Glasgow. Br J Gen Pract 1997;47:635-7.

23 Morin P, De Wals P, Noiseux M, Nivonsenga T, St-Cyr-Tribble D, Tremblay C. Pregnancy planning and folic acid supplement use: results from a survey in Quebec. Prev Med 2002;35:143-9.

24 Perlow J. Comparative use and knowledge of preconceptional folic acid among Spanish- and English-speaking patient populations in Phoenix and Yuma, Arizona. Am J Obstet Gynecol 2001;184:1263-6.

25 Sillender M, Pring DW. How effective was the health education authority's folic acid campaign. J Obs Gynaecol 2000;20:271-6.

26 Tam LE, McDonald SD, Wen SW, Smith GN, Windrim RC, Walker MC. A survey of preconceptional folic acid use in a group of Canadian women. J Obstet Gynaecol Can 2005;27:232-6.

27 Wild J, Sutcliffe M, Schorah C J, Levene MI. Prevention of neural tube defects. Lancet 1997;350:30-1.
28 Joffe M. Decreased fertility in Britain compared with Finland. Lancet 1996;347:1519-22.

29 Joffe M. Time trends in biological fertility in Britain. Lancet 2000;355:1961-5.

30 Axmon A, Hagmar L. Time to pregnancy and pregnancy outcome. Fertil Steril 2005;84:966-74

31 Slama R, Kold-Jensen T, Scheike T, Ducot B, Spira A, Keiding N. How would a decline in sperm concentration over time influence the probability of pregnancy? Epidemiology 2004;15:458-65.

32 Inskip HM, Godfrey KM, Robinson SM, Law CM, Barker DJ, Cooper C, et al. Cohort profile: the Southampton Women's Survey. Int J Epidemiol 2006;35:42-8.

33 Robinson S, Godfrey K, Osmond C, Cox V, Barker D. Evaluation of a food frequency questionnaire used to assess nutrient intakes in pregnant women. Eur J Clin Nutr 1996;50:302-8.

34 Robinson SM, Crozier SR, Borland SE, Hammond J, Barker DJP, Inskip HM. The impact of educational attainment on the quality of young women's diets. Eur J Clin Nutr 2004; 58:1174-80.

35 Jensen TK, Hjollund NH, Henriksen TB, Scheike T, Kolstad H, Giwercman A, et al. Does moderate alcohol consumption affect fertility? Follow up study among couples planning first pregnancy. $B M$ 1998;317:505-10.

36 Goddard E. General household survey 2006. Smoking and drinking among adults, 2006. London, Office for National Statistics, 2008. www.statistics.gov.uk/downloads/theme_compendia/ GHS06/Smokinganddrinkingamongadults2006.pdf.

37 Lakha F, Glasier A. Unintended pregnancy and use of emergency contraception among a large cohort of women attending for antenatal care or abortion in Scotland. Lancet 2006;368:1782-7.

38 Custer M, Waller K, Vernon S, O'Rourke K. Unintended pregnancy rates among a US military population. Paediatr Perinat Epidemiol 2008;22:195-200.

39 Crozier SR, Robinson SM, Borland SE, Godfrey KM, Cooper C, Inskip HM, et al. Do women change their health behaviours in pregnancy? Findings from the Southampton Women's Survey. Paed Perinat Epidemiol 2009 (in press)

Accepted: 10 November 2008 